REVES - Revista Relações Sociais, Vol. OX N. OY (20ZZ)

https://periodicos.ufv.br/reves

elSSN: 2595-4490

REVES-ReVista Relacōes Sociais (eISSN 2595-4490)

\title{
Capital Racial: poder simbólico e estrutura de dominação
}

\section{Racial Capital: symbolic power and domination structure}

Jair da costa Junior

ORCID: http://orcid.org/0000-0002-6418-9020

Universidade Federal de Minas Gerais (UFMG), Brasil

E-mail: jah@ufmg.br / jc.juiorjah@gmail.com

Article Info:

Article history: Received 2021-07-20

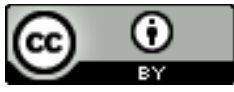

Accepted 2021-10-07

Available online 2021-10-07

doi: 10.18540/revesvl4iss4pp13247-01-13e

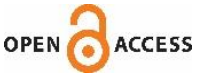

Resumo. O autor apresenta originalidade no olhar concernente à compreensão do racismo enquanto estrutura, suas correlatas consequências e os dispositivos sociais e cognitivos que permitem sua permanência. Resultado de uma instigante e genuína pesquisa qualitativa, onde aplicou-se a técnica de grupo focal junto a jovens negros e brancos, em diálogo a um robusto aparato teórico, o autor construiu o conceito de capital racial e o apresenta como uma chave de compreensão do racismo em sua concepção de estrutura estruturante e um poder simbólico e suas perspectivas paradigmáticas. Em seu desenvolvimento, demostra como o capital racial inculcou (inculca) nos corpos e nas mentes a representação depreciada sobre as pessoas negras, sua cultura e modos de vida e, sobretudo, como esta transita para o universo das relações materiais e econômicas, redefinindo valorações e mantendo intactas, no século XXI, as hierarquias observadas na sociedade colonial. Sob a retórica da cidadania, igualdade de direitos e universalidade a desvaloração simbólica segue definindo o lugar da população negra nas sociedades, em oposição a população considerada branca.

Palavras-chave: Capital Racial. Raça. Identidade. Classe. Estado.

Abstract. The author presents originality in his view concerning the understanding of racism as a structure, its related consequences and the social and cognitive devices that allow its permanence. The result of an instigating and genuine qualitative research, where the focus group technique was applied to black and white youth, in dialogue with a robust theoretical apparatus, the author constructed the concept of racial capital and presents it as a key to understanding the racism in its conception of structuring structure and a symbolic power and its paradigmatic perspectives. In its development, it demonstrates how racial capital inculcated (inculcates) in bodies and minds the depreciated representation of black people, their culture and ways of life and, above 
all, how these transitions to the universe of material and economic relations, redefining valuations and keeping intact, in the 21st century, the hierarchies observed in colonial society. Under the rhetoric of citizenship, equality of rights and universality, symbolic devaluation continues to define the place of the black population in societies, in opposition to the population considered White.

Keywords: Racial Capital. Breed. Identity. Class. State.

\section{Introdução}

Esta contribuição interroga e destaca a tendência de perenização do racismo, abordando de maneira crítica, a modernidade enquanto marco temporal de instituição de um novo sistema mundo e projeto de dominação, compreendida e refletida a partir da redefinição das identidades visando o exercício do poder de um grupo sobre outros. Nesta perspectiva, seja partindo das lógicas de construção identitária ou formação do Estado, há, como plano de fundo, um capital simbólico construído e instituído enquanto insígnia social que permite que as engrenagens sociais e os dispositivos do Estado funcionem de maneira naturalizada no desfavorecimento da população afrodescendente e indígena. Neste sentido, o colonialismo e a gênese do Estado são elementos para compreender como foi gerado e o modo como opera um capital racial enquanto poder simbólico instituído nas relações sociais e oficializado pelo Estado. Desta forma, o artigo apresenta e discute o conceito de capital racial, o qual foi elaborado e refletido originalmente no desenvolvimento de pesquisa de mestrado ${ }^{1}$. O conceito alude às consequências objetivas, proporcionadas por suas raízes e condicionamentos subjetivos, do estabelecimento de distinções e representações sociais construídas a partir de marcadores sociais reconhecidos como raciais que operam na (re)produção de concepções valorativas antagonicamente reforçadas. Capital racial, trata-se, portanto, de uma propriedade do capital simbólico incorporado nas configurações sociais e cognitivas (estruturas sociais/estruturas estruturantes), permitindo, de forma naturalizada, a subtração simbólica de valor e, consequentemente, erigindo barreiras ao reconhecimento social e operando na extração de mais valor de um grupo sobre o outro.

\section{Estrutura "racializada" e a configuração da percepção}

A estruturação das sociedades modernas enquanto arquétipo de um sistema de dominação elegeu e instituiu raça como símbolo de reconhecimento de posições sociais e, a partir de construções históricas, socioculturais e políticas, associada diretamente a capacidades inatas dos seres humanos. Consequentemente, os atributos pelos quais construímos e percebemos o sentido de raças diferentes, como parâmetros de identificação e representação social, fixados de forma diametralmente opostos, remete-nos a uma essência totalizadora do ser em sua identidade racial como coisas da natureza. Raça, comporta, portanto, toda uma concepção discursiva e ideológica em torno da qual se organiza um sistema de poder simbólico, socioeconônomico, genderizado, de exploração, de exclusão e exceção.

A mobilização de atributos reconhecidos como elementos identitários raciais, os quais conformam um sistema de reconhecimento diferencial, balizando a ordem

\footnotetext{
${ }^{1}$ Ver: Costa (2018).
} 
social e atribuindo sentidos às distinções sociais, "legitimam a exclusão racial em termos de distinções genéticas e biológicas" (HALL, 2013, p. 77), e faz-nos recuar a tempos remotos da convivência humana entre povos diferentes, onde "gregos e romanos constituíram um mundo alicerçado sobre a explícita distinção entre 'inferior' e 'superior', 'bárbaros' e 'civilizados'” (MOORE, 2007, p. 55). Limitados em seus próprios domínios, tais classificações sociais eram aplicadas entre grupos exclusivamente brancos (europeus). Foi somente a partir da expansão imperialista e a formação de sociedades multirraciais com a conquista da África do Norte e do Oriente Médio, que as distinções passaram a se orientar em supostas "qualidades e defeitos morais do ser humano segundo critérios baseados puramente no fenótipo" (MOORE, 2007, p. 56). Muito embora os antecedentes destas distinções já indicarem e incidirem sobre aspectos que sugerem a racialização, conforme veremos na sequência, será no mundo árabe islâmico, entre os séculos VII e XIV, que ocorrerá a gestação da escravidão propriamente racial.

Nos mostra Moore, que a "noção de que povos da raça negra desempenharam um papel irrisório na longa e complexa trama da humanidade foi forjada durante o recente período sombrio da História da humanidade, construída pela conquista das Américas e a escravização dos africanos nessas terras" (MOORE, 2007, p. 38). É nesse sentido, que o colonialismo evidencia-nos o marco inicial de um sistema-mundo capitalista/patriarcal/cristão/moderno/colonial europeu, em 1492 (BERNARDINOCOSTA, GROSFOGUEL, 2016) por meio do qual, "a noção de raça se consolidou como princípio organizador que sustentou o desenvolvimento do capitalismo mundial, redefinindo as identidades e rearticulando o universo das relações intersubjetivas de dominação" (QUIJANO, 2005. p. 121). As dimensões deste "sistema mundo" articularam-se de forma a produzir legitimidade para seus empreendimentos e garantir a hierarquização das posições sociais, bem como as relações de poder fundamentadas em supostas disposições raciais. A despeito da modernidade, a retórica angular de desvalorização da vida de grupos etnicamente diferentes já se encontrava elaborada pela dimensão cristã.

"A igreja Copta era uma das mais antigas comunidades cristãs 'ultramarinas', os santos negros surgiam na iconografia cristã medieval", conforme observa Hall (2016. p. 162). Situação que se alterou diante de uma lenda muçulmana que ganhou uma versão bíblica - judaica - visando a naturalização e legitimação da escravização: "filho de Noé, e ancestral dos negros, foi condenado a ser negro por causa de seu pecado. A maldição de ser escravizado foi transmitida a todos os seus descendentes" (MOORE, 2007, p. 86). Em referência à cor da pele, "os africanos foram chamados de descendentes do personagem bíblico Cam, amaldiçoados, tal como o filho deste, Canaã, a ser perpetuamente 'servos dos servos de seus irmãos'” (HALL, 2016. p. 162).

Esta foi uma das narrativas que serviu de sustentação aos propósitos imperialistas da colonização como justificativa para a exploração e extermínio da população negra: a imposição a trabalhos forçados; os maus tratos, estupros e assassinatos eram admitidos contra esses corpos sob a retórica de salvação de suas próprias almas. Fica evidente que o "fenótipo, desde os mais longínquos períodos, determina um papel orientador das ações violentas" (MOORE, 2007, p. 163). Aliando narrativas ideológicas e míticas referentes a inferioridade dos povos de pele escura, especialmente oriundos da África, com práticas de subjugação que os colocavam na condição se seres animalizados, estabeleceu-se "o princípio da escravidão perpétua das pessoas de origem africana, estigmatizadas pela sua cor, tornou-se progressivamente a regra. Os africanos e sua progenitura tornaram-se escravos perpétuos" (MBEMBE, 2018, p. 44). 
É neste contexto global, de expansão do poder mercantil e político da Europa que o território hoje conhecido como Brasil foi anexado como o maior regime escravocrata da história da humanidade em termos numérico, espacial e temporal. Contexto em que os povos - indígenas e africanos - foram submetidos a um processo sistemático de desvalorização da sua condição humana e suas matrizes existenciais. O que proporcionou a perda de poder desses dois grupos, com a consequente e quase total eliminação dos significados de suas práticas nativas, e teve na imposição da religião - cristianismo - um dos principais instrumentos de dominação simbólica, conjugados à constante mobilização e reafirmação de diferenças tidas como raciais.

A imposição de um novo código de regras e a substituição de seus modos de vida, sua cultura e crenças, de modo geral, o sentido da existência - weltanschuung, pertencimento e reconhecimento em grupo por outro, a partir do qual foram desumanizados, pode estar entre os fundamentos de um sentimento de auto inferiorização. No sentido mesmo evocado por Fanon, de que a "civilização branca, a cultura europeia, impuseram ao negro um desvio existencial" (FANON, 2008, p. 30).

A escravização nas várias partes do mundo, embora com algumas estratégias específicas em suas respectivas sociedades, deixa nítido que teve na imposição de representações sociais depreciativas e a violação da subjetividade identitária como seus pontos focais comuns, o que Collins (2019) chamou de "imagens de controle". Regida por uma sistemática garantia de privilégios, concomitante a uma sistemática de exclusão objetiva e simbólica, originou duas classes: a população negra coisificada e tratada como animal, apenas máquina de trabalho; e a parcela branca, nos postos de comando e colhendo os lucros produzidos pelos primeiros. A classificação racial originou "a específica percepção de que o trabalho pago era privilégio dos brancos. A inferioridade racial dos colonizados implicava que não eram dignos do pagamento de salário. Estavam naturalmente obrigados a trabalhar em benefício de seus amos" (QUIJANO, 2005. p. 120).

As bases desse sistema remontam a tempos antigos e foram atualizadas conforme o contexto político. Igualmente as teorias da fisiognomia, na Grécia e Roma antigas, em que se mobilizou o "raciocínio supostamente científico baseado no conceito de fenótipo racial" (MOORE, 2007, p. 57), a partir do qual, as características dos povos africanos foram invariavelmente convertidas em atributos negativos, as teorias raciais do século XIX, no Brasil e no mundo, sustentadas numa lógica de "evolução humana" cumpria a função de desumanizar negros, indígenas e mestiços. Buscava-se justificar com o estatuto de ciência, as mais variadas concepções opositoras e binárias, alicerçadas em imaginários racialistas de senso comum, o que consubstanciava, consequentemente, a formulação de projetos e políticas conservadoras com base no pensamento colonial. Como parte deste projeto, justificavam-se a partir de supostas inferências científicas, sustentadas no mito da baixa capacidade cognitiva das raças não brancas, a permanência das rígidas hierarquias observadas na estrutura social. Por supostos critérios científicos, que nada mais eram que percepções racistas do mundo aplicadas e reproduzidas no âmbito da ciência, permitia remontar, a partir de velhos parâmetros, discussões sobre a igualdade (ou desigualdades) entre os homens e mulheres. No século XIX essa tendência inundou o campo científico contribuindo para solidificar "as imagens de controle surgidas na era da escravidão e ainda hoje aplicadas" (COLLINS, 2019, p. 35).

Neste sentido, foram apontadas como supostas explicações sobre obstáculos ao desenvolvimento do país, em razão da presença de "raças inferiores", bem como a mobilização de diferenças sociais e raciais como critérios para acesso à cidadania. 
Com respaldo social e a legitimidade conferida aos estudos científicos, suas conclusões não claudicariam a reverberar como verdade no espaço social e serviriam às instituições de controle, especialmente no campo da segurança pública. Assevera Mbembe (2018, p. 86), que "se existe um inconsciente racial da política negra do mundo contemporâneo, é nesse falso saber e nessa primitiva psicologia dos povos e das emoções herdadas do século XIX que deve ser procurado".

Estes marcos analíticos são imprescindíveis para refletirmos em termos de incorporação de significados de práticas sociais. Por meio de um código de regras tacitamente compartilhado que atribui sentido ao comportamento social de um povo, o qual se configurou em torno de uma robusta população negra mantida escravizada e diferenciada pelo trato nas relações cotidianas. Tais ocorrências se deram a partir dos símbolos de distinção, que se tornaram, por excelência, de dominação e subordinação e permeiam as relações intramundanas. Tais relações, são marcadas de forma emblemática, pelas distinções e pelas violências objetivas perpetradas contra os corpos das pessoas negras e indígenas, pelos constantes homicídios e estupros, como suposto direito das pessoas brancas, ou por outras formas por elas autorizadas.

O modus operandi do colonialismo alimentou a banalização da vida das pessoas negras, indígenas e suas culturas, como aspectos de uma prática social que contribuiu continuamente para manutenção de uma representação social destes grupos como seres inferiores, sem valor e, consequentemente, corroborando o estatuto de pessoas matáveis. Essa dinâmica forjou a instituição de um "capital racial": um mecanismo de dominação subjetiva que se opera no nível da percepção dos agentes, indistintamente, condicionando e nivelando o entendimento referente ao sentido incutido sobre a cor da pele e os traços fenotípicos.

Uma barreira simbólica construída de maneira que, ao operar no nível da percepção dos agentes, controla e ordena, segundo seus parâmetros, todas as dimensões da vida de uma sociedade. Consequentemente, influindo e moldando toda a dinâmica social no ordenamento das posições dos agentes em consonância a tal simbologia. É por meio da percepção que os agentes distinguem o que é importante do que é insignificante, raro ou banal. Dito de outra forma, nossa percepção, essa configuração do mundo que atribui sentidos ao nosso senso moral, é responsável pelos princípios de julgamento que motivam e dão vida às nossas ações. Tais princípios de julgamento explicitam, grosso modo, atos políticos que possuem a finalidade de impactar a dinâmica social no estabelecimento do "ordenamento societal", exercendo funções de disciplinarização e regulação, de reconhecimento e exclusão.

Com o advento da sociedade de classes e a manutenção da hierarquia social colonial no Estado moderno, houve uma homogênea polarização da concentração racial nas distintas classes sociais. Fator que facilitou a associação, embora insciente e obtusa, das distinções de classes e seus respectivos condicionamentos às categorias raciais antagonicamente posicionadas, mantendo e reforçando o mito da superioridade racial, agora convertido e "ratificado" em ideologia do desempenho. Assim, seguiu-se na retroalimentação da ideia de um valor diferencial entre os seres humanos, na legitimação da desigualdade e ofuscando, consequentemente, o caráter violento e "racializado" das desigualdades sociais, bem como seus estreitos vínculos com a sociedade colonial. Nesse sentido, é relevante destacar as palavras de Mbembe (2018, p. 76), que afirma "que raça e racismo estão ligados a antagonismos que se ancoram na estrutura econômica das sociedades [...] ao longo de grande parte da história moderna, raça e classe mantiveram laços de coconstituição". Na mesma perspectiva que Mbembe, Fanon (2005) observa que, especialmente em países de 
passado colonial, a infraestrutura é também a superestrutura, em que as nações supostamente independentes, quase como uma condição natural ou destino, se viram obrigadas a dar continuidade aos velhos circuitos econômicos instalados pelo regime colonial.

Nesta perspectiva, capital racial caracteriza-se por suas peculiaridades de um poder simbólico sendo operacionalizado em favor de um sistema de dominação na manutenção de uma estrutura social que se autorregula de forma a perpetuar as desigualdades. Assim, seu reconhecimento, também evidenciado no desconhecimento, torna-se o abrigo tenaz que confere eficácia a este poder. Pressupõe a aceitação e reciprocidade de uma sociedade expressa a partir do consenso (e no silêncio). Poder que somente pode ser exercido com o consentimento dos envolvidos, expondo seu enraizamento nas consciências e pressupondo a naturalização, tanto pelos dominadores quanto pelos dominados, "de uma rede de mecanismos automáticos de controle e submissão que dispensam os instrumentos de negociação propriamente grupal" (MOORE, 2007, p. 265). Além disso, permite extrair o equivalente, em termos de dominação objetiva, ao que seria alcançado pelo uso da força física/bélica - embora tal força componha este sistema, sendo legitimada no monopólio estatal da violência.

Falar em raças distintas é considerar, como partes da mesma moeda, identidades relacionadas às raças em questão. Identidades que são constituídas a partir de uma relação de oposição, em que a diferença desveladora do sentido da representação é fruto de um processo exógeno de reconhecimento, a partir do outro, construído e incorporado nas relações sociais. "Tais práticas de significação que produzem significados envolvem relações de poder, incluindo o poder de definir quem é incluído e quem é excluído" (SILVA, 2014. p. 19).

Apesar de não serem fixas, as identidades são historicamente construídas e socialmente concebidas como tal, o que impõe a construção de arquétipos identitários opostos que lhes dotam de sentido, estabelecendo, diametralmente, o legítimo e o ilegítimo, "o sagrado" e "o profano", o bom e o ruim. É nesse sentido que a instituição de um capital racial, enquanto dispositivo do capital simbólico de uma sociedade, ao agregar todas as perspectivas morais positivas enquanto essência da identidade europeia (branca), estabeleceu um parâmetro simbólico de relações intersubjetivas que partem do pressuposto de uma superioridade natural em relação às demais identidades e culturas, as quais passaram a serem consideradas raças inferiores e desprovidas de valor. Segundo Silva,

fixar uma identidade como a norma é uma das formas privilegiadas de hierarquização das identidades e das diferenças [...] normalizar significa atribuir a essa identidade todas as características positivas possíveis, em relação às quais todas as demais só podem ser avaliadas de forma negativa" (SILVA, 2014, p. 83).

O que está em jogo na construção das identidades na modernidade situa-se na fronteira entre a exclusão e o reconhecimento, sendo assim, o sentido construído e apreendido sobre cada uma. Conforme nos ensina Hall, os signos carregam dois elementos estruturantes que são: o significante e o significado. O primeiro elemento é a imagem que se correlaciona ao segundo, que é seu conceito, grosso modo, um é forma e o outro o conteúdo (ideia), respectivamente. "Os dois são necessários para produzir sentido, mas é na relação entre eles, sustentada no nosso código cultural e linguístico, que sustenta a representação" (HALL, 2016. p. 57). Sobremaneira, o 
sentido se torna mais inteligível e desvela o que subjaz sua lógica de fato na demarcação da diferença, por entendimentos de oposição binária, de polaridade. 0 resultado prático da relação com o signo torna-se compreensível e passível de interpretação, a partir da construção do sistema de significados de nossa cultura, expressos nas manifestações explícitas ou tácitas, objetivas e simbólicas, pelos agentes que compartilham uma linguagem comum.

O conceito de capital racial nos auxilia na compreensão sobre a funcionalidade da utilização das distinções sociais construídas em torno de suposições tidas como raciais, visando consubstanciar a permanência da exploração sistemática e do genocídio da população negra. Consiste na efetivação de uma linguagem prática, que atribui valor às características reconhecidas como pertencentes às identidades raciais, de forma que passam a ser oficializadas pelas instituições reconhecidas como oficiais. Pois, é desta maneira, que "o Estado contribui para sua política e uma unificação do mercado das trocas simbólicas, isto é, o mercado das posturas, das maneiras, da roupa, da pessoa, da identidade e da apresentação", [bem como, da representação] (BOURDIEU, 2014. p. 148).

Diante de tal perspectiva, é importante salientar que a configuração desse sistema de percepções, produzido e mediado por práticas e representações, apresenta-se aos sujeitos que compartilham do mesmo código de comportamento a partir da linguagem ${ }^{2}$, de forma indistinta, como realidade inquestionável. Como nos evidencia Mbembe (2018, p. 61) sobre a razão negra, trata-se de "um sistema pretensamente erudito de narrativas e discursos. É igualmente um reservatório de onde a aritmética da dominação de raça retira suas justificações". E, capital racial nada mais é que este poder simbólico fundado e instituído como parte da linguagem das sociedades de passado colonial, que transmutado e incorporado como senso comum e habitus e exercido do trato mais banal das relações sociais, às decisões políticas complexas, com reverberações no ordenamento da dinâmica social e, portanto, desconhecido em sua dimensão de violência;

designa um conjunto tanto de discursos como de práticas - um trabalho cotidiano que consistiu em inventar, contar, repetir e promove a variação de fórmulas, textos e rituais como o intuito de fazer surgir o negro enquanto sujeito racial e exterioridade selvagem, passível de desqualificação moral e instrumentalização prática (MBEMBE, 2018, p. 61).

\section{Racismo naturalizado: capital racial}

A cor da pele pode ser compreendida, partindo do sentido que a percepção comum Ihe atribui, como paradigma subjetivo inscrito na dimensão objetiva da realidade do mundo social, a partir da representação social apreendida em relação a cada tonalidade e suas gradações, funcionando como ordenador das relações sociais e simbologia de reposicionamento e reconhecimento social (ou não) dos agentes no espaço social. Uma vez imposta como padrão universal estético e cultural nos "sistemas pigmentocráticos", há reservas de privilégios intermediários, já que sociedades multirraciais são regidas por gradações e variações fenotípicas

2 Entendida em sentido amplo e inclusivo, abarcando as mais diversas formas de estabelecer comunicação. Ver: Hall (2016). 
parametrizadas por uma norma denominada como "imagem somática normativa3" (MOORE, 2007). Para Beatriz do Nascimento, o grande drama da população negra é a ausência de reconhecimento social, sendo a questão econômica uma dimensão secundária (NASCIMENTO, 2018). Muito embora, em grande medida, sejam elementos interdependentes. Compreende a autora, que o principal documento que resiste, insere e identifica a/o negra/o na sociedade brasileira é o fenótipo, este corpo que apresenta diferenças socioculturais e sugere um período na história das sociedades e uma "georeferenciação";

esse corpo negro ainda que parado para falar ou fixado em fotografia enuncia sentidos. Na memória corporal ou na difícil construção da cidadania, a linha do corpo negro continua desenhando o espaço. Fio da memória. Fio da identidade. Espelho que nos indaga. Da cabeça aos pés, repleta de signos, a imagem no espelho fala ao corpo que desenha o espaço. A todo lugar e momento os dois se fazem perguntas que tão cedo não irão se calar. (NASCIMENTO, 2018, p.69).

Lida social, política e culturalmente como insígnia de reposicionamento social, a cor da pele assume o status de signo e passa a operar como um capital racial. Associada diretamente à noção de raça, a cor da pele é mobilizada como parâmetro de mensuração e definição de concepções valorativas sobre a pessoa e o grupo social ao qual indica pertencer. Segundo Mbembe (2018), raça constitui-se como um signo, remetente à simbologia das cores, que transforma pessoas em corpos de extração e sujeitos raciais; sendo o negro, "aquele cuja a vida é feita de resíduos calcinados" (MBEMBE, 2018, p. 81). Partindo da observância de traços fenotípicos, entre os quais a cor da pele assume predominância, "pois, existe como uma realidade irrecusável" (MOORE, 2007, p. 166), transmuta-se no fundamento de definição das hierarquias e papéis de poder ou, por outro lado, presume-se ou constata sua ausência.

Nesse sentido, a categoria trabalho é central para essa compreensão, uma vez que, "num mundo cujos principais valores são ditados pelo trabalho, isto é, onde todas as atividades humanas se resumem a trabalhar" (ARENDT, 1989. p. 527), a "divisão racial do trabalho" (GONZALEZ, 2018) ordena uma concepção de valor sustentada nos princípios de visão e divisão do mundo, entre os quais, o parâmetro da "raça" assume centralidade.

Dessa forma, o "animal laborans cujo necessário 'metabolismo com a natureza' não é do interesse de ninguém" (ARENDT, 1989. p. 527), instaura um contraponto vital e valorativo com a "competência-máquina" (FOUCAULT, 2008), exaltada no contexto político da modernidade. Podemos pressupor que ao animal laborans estejam compreendidas as habilidades para a produção direta, material, força bruta de trabalho e a baixa aptidão intelectual. Já a "competência-máquina" pressupõe a posse de habilidades intelectuais, de uso da racionalidade e capacidades cognitivas complexas e variadas. Tais atributos informam da relação antagônica entre "razão e corpo", definindo polos valorativos e hierarquizantes (superior/inferior) para os indivíduos referenciados em cada um dos polos raciais. O que acarreta efeitos na

\footnotetext{
${ }^{3}$ A norma, ou imagem somática normativa, refere-se à estética e cultura branca, europeia, como padrão identitário universal.

4 Um dos princípios basilares da estrutura de conhecimento ocidental e da lógica epistemicida fundamentadora da hegemonia euro-norte-americana, que subjaz uma lógica opositora e racialista sobre capacidades cognitivas entre os grupos humanos. Ver: Grosfoguel (2016)
} 
acumulação de capital econômico/cultural/social, na representação social, no reconhecimento social e no espaço social, condicionando a elaboração de sentido como plano de fundo das relações sociais, por extensão do universo simbólico.

O controle de acesso às posições socioprofissionais de status privilegiado, associado às distinções sociais, funcionando como preditoras de uma suposta essência conferida pelas diferenças "reconhecidas" como raciais, foi a forma mais eficaz de controle das hierarquias sociais, manutenção de privilégios e a subtração simbólica do valor das pessoas negras e, consequentemente, a inferência de um capital humano inferior.

Capital racial, portanto, não se restringe meramente à estética identitária "racializada", mas, sobretudo, ao sentido construído social, histórica e politicamente em torno da noção de raça. Apesar de estar associada diretamente ao fenótipo, deve ser compreendido como uma relação social. Neste entendimento, o fenótipo como estética identitária que remonta à noção de raça agrega, em sua composição, uma série de atributos sociais como o jeito de andar, de falar, de se vestir, de gesticular, localização geoespacial, bem como de hábitos e costumes, músicas até produtos de consumo que são associados a cada uma dos pólos raciais em relação de forma essencialista e binária. São elementos constituintes das pessoas, reivindicam reconhecimento identitário e configuram as percepções sobre as pessoas, os grupos e classes.

Neste caso, uma fonte de energia social que existe e é mobilizada objetivamente produzindo efeitos no ordenamento do espaço social, tecnologias e dispositivos de instrumentalização que tem como resultado a atribuição de valores. Estes, transitam, do universo simbólico ao material, numa confluência harmônica compondo o senso de realidade na retroalimentação do senso comum e do habitus.

No contexto da imanência de um capital racial, enquanto capital simbólico de uma sociedade, a noção de "raça é, na melhor das hipóteses, um indicador precário de capacidade" (APPIAH, 1997, p. 65) que será lido a partir dos elementos distintivos reconhecidos ou não no trato social. Capital racial diz respeito a uma afiliação do capital simbólico, que também pode ser definido como distinção social. Trata-se, segundo Bourdieu, de "uma propriedade qualquer (de qualquer tipo de capital, físico, econômico, cultural, social) percebida pelos agentes sociais cujas categorias de percepção são tais que eles podem entendê-las (percebê-las) e reconhecê-las, atribuindo-Ihes valor" (BOURDIEU, 1996. p. 107).

Como nos mostra Fanon (2005, p. 56),

A originalidade do contexto colonial é que as realidades econômicas, as desigualdades e a enorme diferença dos modos de vida não conseguem mascarar as realidades humanas. Que se percebe na sua imediatez $o$ contexto colonial, é patente que aquilo que fragmenta $o$ mundo é primeiro o fato de pertencer ou não a tal espécie, a tal raça.

As distinções enquanto transfigurações simbólicas das diferenças socialmente construídas e racialmente atribuídas, são produtos da aplicação dos esquemas de construção do mundo social e seu reconhecimento, bem como sua legitimidade traduz-se na apreensão do mundo como algo evidente e natural, de forma a fazer crer que haja uma essência que condiciona os agentes, os grupos ou as classes à determinada situação, coincidindo com as evidências que se observam na dinâmica social objetiva e das estruturas incorporadas.

Amparado no habitus de uma sociedade, o poder simbólico constitui-se como violência invisível - aquela é exercida sob a forma mais sutil, da violência simbólica 
como violência despercebida. Inserida nas práticas sociais cotidianas, termina por passar como um trato comum, normal e natural das relações sociais historicamente legitimadas. É nesta concepção, que por habitus subentende-se uma visão de mundo incorporada, que espontaneamente subjaz uma hierarquia racial associada às percepções morais, que se acumula e se solidifica como signo social naturalizado, produzindo valores distintivos sobre tudo que compõe nosso universo social; que é, por condicionamento do capital racial, um universo social racializado.

As diferenças culturais são produtos de uma dialética histórica de consagração de distinções e sentidos cumulativamente incorporados e socialmente reproduzidos. Quando analisamos criticamente a história da colonização das Américas, especialmente da América do Sul, percebemos que as distinções foram criadas com a finalidade de justificar as violências, e, de modo especial, a exploração do povo negro.

É relevante, portanto, considerar o conceito de capital racial enquanto categoria "semântico-conceitual", prática e relacional, partindo da premissa de uma compreensão que subjaz a categoria discursiva e fantasmática referente a raça (MBEMBE, 2018), bem como a instituição da divisão racial do trabalho e do valor diferencial atribuído em relação ao fenótipo racial observado, em âmbito global. É por meio do imaginário social, constituído a partir de representações que se percebe a desvalorização das pessoas negras, materializada nas sutilezas observadas a partir das trocas simbólicas, em forma de exclusão social objetiva e retratadas na desigualdade social. Um tipo de sutileza que se opera por meio do princípio da exceção, tendo como fundamento a exclusão. Uma espécie de "exclusão inclusiva [...] na qual a vida é incluída em seu ordenamento unicamente sob a forma de sua exclusão (ou seja, de sua absoluta matabilidade)" (AGAMBEN, 2004. p. 16).

Partindo da construção histórica, política e social, que pesa sobre a população negra em âmbito mundial, não seria leviano considerar a permanência da "crença" de um capital humano baixo como precondição genética - o que pode ser explicado pela imanência do "mito-ideologia" da superioridade racial. Assim, controlado por um rigoroso arcabouço de distinções sociais, que se opera a partir das relações intersubjetivas (práticas) e mecanismos (biopolítica) de Estado, esse "mito-ideologia" se apresenta como ponto de referência, uma norma-padrão estética e cultural.

A maldição de Cam, acrescida da retórica da inferioridade racial, já incutia uma base de valoração negativa, que se sedimentou ao longo dos séculos e encontrou no mito da democracia racial o fôlego necessário para seu enraizamento nas sociedades. Raça é filha do racismo e não o contrário (MBEMBE, 2018).

O exemplo histórico e politicamente inegável está no programa de incentivo à imigração de europeus ao Brasil. Este se baseava na premissa de que a partir do cruzamento entre as raças haveria a prevalência da raça branca ${ }^{5}$, especificamente de seu fenótipo. Nesse caso, o subtexto é de uma superioridade genética da raça branca em relação à negra, convocada para aniquilar ou salvar a população negra de uma vida indigna de ser vivida; "a raça é uma das matérias-primas com as quais se fabrica a diferença e o excedente, isto é, uma espécie de vida que pode ser desperdiçada ou despendida sem reservas", enfatiza Mbembe (2018, p. 73).

A necessidade de extermínio biológico e fenotípico da população negra parte da suposição de uma inferioridade e degenerescência que é, grosso modo, racial. Nessa perspectiva, encontra-se novamente a proposição de salvação das almas dos

\footnotetext{
${ }^{5}$ Estimava-se que em 2012, a raça negra (fenótipo) não existiria em território no Brasil. Ver, Souza (2012).
} 
descendentes de Cam, através da "elevação" do capital humano (genético) da população negra. Encontra-se, como fundamento de ações dessa natureza, a eliminação do fenótipo, mas, sobretudo, do patrimônio genético da/o negra/o. Conforme constata Moore (2007, p. 264), "a obsessão com a 'mestiçagem' é vista como a necessidade de 'apagar' o fenótipo do Outro Total”.

Capital racial implica na evidência prática e objetiva de atribuição valorativa, que encontra ressonâncias nas formas de "inclusão-exclusão". É uma propriedade essencialmente relacional, assim como qualquer outra propriedade do capital simbólico. Enquanto propriedade intrínseca das relações sociais compreende as classificações e hierarquizações que podem ser observadas nas distinções imputadas à população negra, que por sua vez, expressam um conjunto de valorações morais e competências sociais, as quais determinam ou condicionam o valor no mercado (das trocas simbólicas e econômicas). Vale demarcar, que o mercado das trocas simbólicas e o mercado das trocas econômicas funcionam como instâncias intimamente interligadas e intrainfluintes, condicionadas que são pelos mesmos princípios de atribuição de valores praticados nas respectivas sociedades, segundo seus critérios de distinção, classificação e hierarquização por meio de acordos tácitos.

\section{Considerações Finais}

Sustentado em uma pesquisa empírica, este artigo apresentou parte da discussão teórica que fundamentou e construiu o conceito de capital racial a partir das percepções dos interlocutores que dela participaram. Articulado a diversas teorias que auxiliaram na compreensão do material, foi possível apreender o sentido que subjaz as práticas sociais e ideologias raciais que condicionam a diferenciação, a depreciação e exclusão de pessoas negras, indígena se não brancas. Reportando a fatos históricos e teorias produzidas em torno dos fenômenos ocasionados pelas ideologias raciais, bem como às práticas que as caracterizam e explicitam seus fundamentos, procurei demonstrar como um contexto social, cultural e político, através de suas linguagens, reproduzidas e reforçadas ao longo de séculos produziu um capital simbólico, no caso o capital racial, capaz de ordenar sociedades prol de seus princípios. Um poder simbólico que está ligado à gênese de nossa sociedade, bem como da constituição do mundo moderno, portanto, de ordem estrutural. Capital racial se constitui como o princípio de ordenamento do mundo moderno, como um dispositivo que propicia a manutenção das hierarquias, representações e classificações sociais observadas na sociedade colonial. Um dispositivo localizado na dimensão subjetiva, tanto nas estruturas sociais quanto nas cognitivas, capaz de produzir severos impactos na realidade social e permanecer, ainda no século XIX, na ordem do oculto para muitas e muitos pesquisadores, cientistas e intelectuais. Mais algumas palavras:

O colonialismo, em suas dimensões globais, legou às sociedades ocidentais e ocidentalizadas, cunhando no código de comportamento dos seres humanos, 0 desvalor sobre as pessoas negras como condicionamento dos esquemas mentais e princípios valorativos de classificação do mundo social. A construção social que permite que a cor da pele e traços fenotípicos figure como parâmetro de mensuração do nivelamento social, situa-se na fronteira entre o simbólico e o material, o objetivo e o subjetivo, e determina a produção de mais valor à medida que tem sua condição ordenada socialmente, regulada e oficializada pelo Estado. A exploração da população negra nas Américas tem como principal produto da colonização, o que hoje rende mais lucros que naquele período, uma expressiva exploração das 
representações sociais, funcionando como mecanismos de controle, com a finalidade precípua de incutir uma auto-percepção inferiorizada, e também imobilizar essa parcela da população. Dessa forma, o capital racial, compreendido e interpretado a partir de uma vasta gama de marcadores raciais/sociais, define privilégios (pessoas brancas) e exclusões (pessoas negras).

No curso de uma experiência histórica e no aprendizado de uma consciência social e política da vida em sociedade, de forma geral, houve uma construção em torno da ideia de raça, que se opera no plano das relações sociais que a transformou no principal capital simbólico, o capital racial, como mecanismo de controle e, consequentemente, produtor de valores no âmbito das relações sociais, políticas e econômicas das sociedades modernas.

\section{Referências}

AGAMBEN, Giorgio. Estado de exceção: homo sacer, II, I. São Paulo: Boitempo, 2004.

ARENDT, Hannah. Origens do totalitarismo. São Paulo: companhia das letras, 1989.

BERNARDINO-COSTA, GROSFOGUEL, Ramón. Decolonialidade e perspectiva negra. Revista Sociedade e Estado. (31) 1, 15-24. 2016. Acesso em: 18 jun 2017. Disponível em: http://www.scielo.br/scielo.php?script=sci_arttext\&pid=S010269922016000100015.

BOURDIEU, Pierre. Razões práticas. São Paulo: Papirus, 1996.

BOURDIEU, Pierre. Sobre o Estado. São Paulo: Companhia das letras, 2014.

COLLINS, Patrícia Hill. Pensamento feminista negro: conhecimento, consciência e a política do empoderamento. São Paulo: boi tempo, 2019.

COSTA, Jair. Genocídio: o apagamento de uma identidade. 2018. $473 \mathrm{f}$ Dissertação (Mestrado) - Programa de Pós-graduação em Ciências Sociais da Pontifícia Universidade Católica de Minas Gerais, Belo Horizonte, 2018.

ELIAS, Norbert. Os Alemães. Rio de Janeiro. Jorge Zahar, 1997.

FANON, Frantz. Pele negra, máscara branca. Salvador: EDUFBA, 2008.

FANON, Frantz. Os condenados da Terra. Juiz de Fora: Ed. UFJF, 2005.

FOUCAULT, Michel. O Nascimento da biopolítica. São Paulo: Martins Fontes, 2008. GONZALEZ, Lélia. Primavera para as rosas negras. [S.I]: Diáspora africana, 2018.

GROSFOGUEL, Ramón. A estrutura do conhecimento nas universidades ocidentalizadas: racismo/sexismo epistêmico e os quatro genocídios/epistemicídios do longo século XVI. Sociedade e estado, Brasília, v.31 n.1, p.25-49, 2016. Disponível em: <https://www.scielo.br/scielo.php?script=sci_arttext\&pid=S0102$69922016000100025 \&$ lng=pt\&tlng=pt>. Acesso em: 10 mai 2021.

HALL, Stuart. Da diáspora: identidades e mediações culturais. Belo Horizonte: Editora UFMG, 2013.

HALL, Stuart. Cultura e representação. Rio de Janeiro: Ed Puc - Rio, 2016.

MBEMBE, Achille. Crítica da razão negra. São Paulo: n-1 edições, 2018.

MOORE, Carlos. Racismo \& sociedade: novas bases epistemológicas para entender o racismo. Belo Horizonte: Mazza edições, 2007.

NASCIMENTO, Abdias. 0 genocídio do negro brasileiro: processo de um racismo mascarado. São Paulo: perspectivas, 2016.

NASCIMENTO, Maria Beatriz. Quilombola e intelectual: possibilidades nos dias da destruição. Diáspora africana: Editora Filhos da África, 2018. 
QUIJANO, Anibal. Colonialidade do Poder, eurocentrismo e América Latina. Clacso. 2005.

SANTOS, Ricardo Ventura. O Congresso Universal de Raças, Londres, 1911: contextos, temas e debates. Boletim do Museu Paraense Emílio Goeldi. Ciências Humanas, 2012. v. 7, n. 3, p. 745-760. p. 756. Disponível em: <http://www.scielo.br/scielo.php?script=sci_abstract\&pid=S1981-

$81222012000300008 \&$ Ing=pt\&nrm=iso $>$. Acesso em 10 set. 2018.

SILVA, Tomaz Tadeu. A produção social da identidade e da diferença. n: SILVA, Tomaz Tadeu. Identidade e diferença: a perspectiva dos estudos culturais. Petrópolis, RJ: Vozes, 2014. 